\title{
A Brief History of the Bioengineering Institute of California and the UC System-wide Symposia
}

\author{
SHU CHIEN ${ }^{1,2}$ \\ ${ }^{1}$ Bioengineering Institute of California, University of California, La Jolla, CA, USA; and ${ }^{2}$ Department of Bioengineering \\ and Institute of Engineering in Medicine, University of California, San Diego, 9500 Gilman Drive, La Jolla, \\ CA 92093-0427, USA
}

(Received 5 February 2011; accepted 24 February 2011; published online 8 March 2011)

Associate Editor Daniel Takashi Kamei oversaw the review of this article.

\begin{abstract}
The plan to establish a Multicampus Research Unit (MRU) on Bioengineering in the University of California (UC) System started in August 1999. The cooperative efforts of the UC campuses led to the formal establishment of the Bioengineering Institute of California (BIC) in October 2003. Three years prior to the BIC establishment, the Systemwide Annual Bioengineering Symposium was started at UC Davis. The Symposia were then hosted sequentially by UC Santa Barbara, UC Berkeley, UCSD, UC Santa Cruz, UC Irvine, UCSF, UCLA, and UC Riverside, with the completion of the first cycle of a decade in the newest campus of UC Merced in 2009. The second cycle began in 2010 with the Symposium returning again to UC Davis. Each campus hosted a wonderful Symposium, with the active participation of students and faculty from all campuses, with the motto of "Ten campuses united as one, learning and growing together." These Symposia have contributed significantly to the collaborative research and training of students and young scientists in bioengineering, as well as fruitful interactions with industry and government agencies, which have provided strong support for these valuable meetings. The BIC will endeavor to further enhance these efforts by fostering research collaborations and joint education and training activities, with the ultimate goal of advancing bioengineering for the improvement of human health and wellbeing.
\end{abstract}

Keywords-Annual symposium, Education and training, Multi-campus research unit, Research collaboration, University of California.

Near the end of the twentieth century, the majority of the University of California (UC) campuses had active programs in bioengineering (BE) or biomedical engineering (BME) - these two terms are used

Address correspondence to Shu Chien, Department of Bioengineering and Institute of Engineering in Medicine, University of California, San Diego, 9500 Gilman Drive, La Jolla, CA 92093-0427, USA. Electronic mail: shuchien@ucsd.edu interchangeably in this article. Several new BE/BME programs were initiated during the last decade before the turn of the century, and those that had begun earlier became increasingly more active. For example, UCSD had a Bioengineering Program since 1966 (in the Department of Applied Mechanics and Engineering Science, as a joint program with the School of Medicine), and it became a Department of Bioengineering in 1994. In 1998, a Department of Bioengineering was also established in UC Berkeley jointly with UCSF, as an outgrowth of a joint graduate program. Discussions among colleagues in the UC campuses led to a consensus that it would be desirable to synergize the excellent and blossoming research and educational activities of all UC campuses by forming a UC Multi-campus Organized Research Unit (MRU).

In August 1999, at the occasion of the 80th birthday celebration for Professor Yuan-Cheng (Bert) Fung, founder of the UCSD Bioengineering Program, I invited leaders in bioengineering from the other UC campuses to come to San Diego to participate in the celebration and to discuss the possibility of forming an MRU dedicated to the synergism and collaboration in bioengineering among all campuses. The meeting was held on August 12, 1999, in the UCSD Faculty Club with attendance by Stanley Berger and Thomas Budinger from UC Berkeley, Steve George from UC Irvine, Katherine Ferrara, Maury Hull, and Scott Simon from UC Davis, Chih-Ming Ho from UCLA, Ashok Mulchandani and John Shyy from UC Riverside, and David Gough, Andrew McCulloch, Geert Schmid-Schönbein, and I from UCSD (Fig. 1).

Following very fruitful discussions, the group decided unanimously to form an MRU on Bioengineering in the UC System. Knowing that the approval of an MRU would take some time, we decided on carrying 


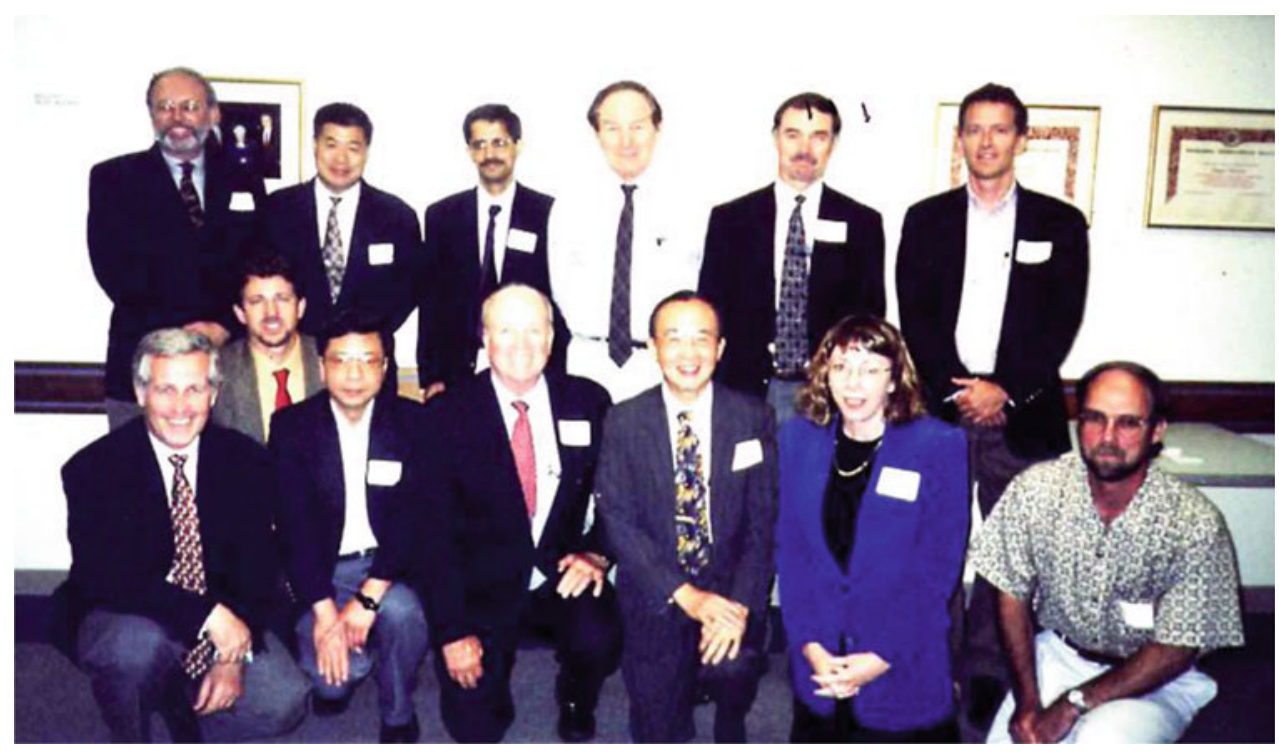

FIGURE 1. The first planning meeting to establish a UC System-wide Multi-campus Research Unit on August 12, 1999, in the Faculty Club of UCSD. Front ( $L$ to R): Geert Schmid-Schönbein, Scott Simon, Chih-Ming Ho, Thomas Budinger, Shu Chien, Katherine Ferrara, Andrew McCulloch. Back (L to R): David Gough, John Shyy, Ashok Mulchandani, Stanley Berger, Maury Hull, Steven George.

out the function of an MRU before the formation of its structure. The function we chose was to hold UC System-wide Annual Bioengineering Symposia that would rotate among all UC campuses, with the goal of bringing together faculty and particularly students for collaborations in research and education. Our colleagues from UC Davis (Maury Hull, Katherine Ferrara, and Scott Simon) volunteered to be the first campus to lead this effort, leveraging on their experience in organizing the UC Davis Biomedical Engineering Symposia that had the participation of UC Berkeley and other neighboring universities. The First UC System-wide Annual Bioengineering Symposium held at UC Davis in May 2000 was a great success (Fig. 2). There were 100 attendees from the nine campuses (UC Merced was not yet formed at that time).

Following a meeting of campus representatives at UC Berkeley on March 13, 2000, a group of us worked on the proposal for the establishment of this MRU, with the first draft written on April 8, 2000. Subsequently, the draft proposal went through nearly 20 revisions, some within our group and others requested by the various committees and Office of the President of the University of California (UCOP), as well as the individual campuses. Finally, the proposal was officially approved by UCOP on October 16, 2003, 4 months after the fourth System-wide Symposium held at UCSD (Fig. 3).

The MRU was named the Bioengineering Institute of California (BIC), with its headquarters at UCSD. The goal of the BIC is to synergize the strengths and expertise on all UC campuses, and foster the cooperation among them to create a coherent and cohesive network for sharing of resources and exchange of information.

By the time of the forming of the BIC and shortly thereafter, additional new departments were established in several UC campuses. These include UC Davis (Biomedical Engineering, 2001), UC Irvine (Biomedical Engineering, 2001), UCLA (Bioengineering, 2002), UC Santa Cruz (Biomolecular Engineering, 2002), UC Riverside (Bioengineering, 2004), and UCSF (Bioengineering and Therapeutical Sciences, 2009). UC Santa Barbara has a Biomolecular Science and Engineering Program and is planning to form a department. UC Merced has Bioengineering as one of its five majors in its School of Engineering. Table 1 provides a summary of the current leadership in $\mathrm{BE} /$ BME in the 10 campuses and the web addresses of the Department/Program.

During its first decade, the Annual Symposia rotated through all 10 UC campuses: UC Davis, UC Santa Barbara, UC Berkeley, UCSD, UC Irvine, UC Santa Cruz, UCLA, UCSF, UC Riverside, and our newest campus UC Merced (Table 2). It was during the Symposium in UC Berkeley in 2002 that the motto of "Ten campuses united as one, learning and growing together" was initiated. The display of photos from the 10 campuses (Fig. 4) and the involvement of Telemedicine and Advanced Technology Research Center (TATRC) began at UC Riverside in 2008. These wonderful symposia were made possible by the superb organizational efforts of the 10 campuses and the 


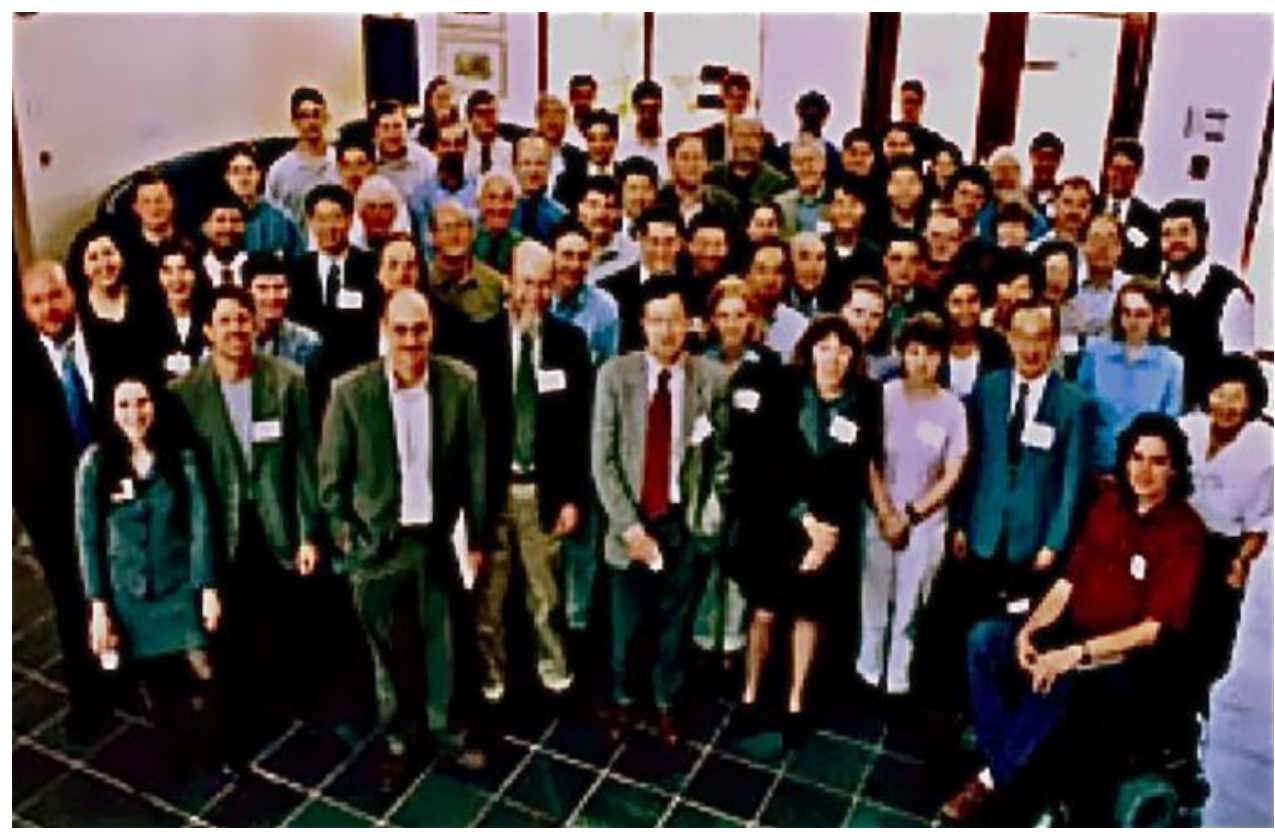

FIGURE 2. The First UC System-wide Annual Bioengineering Symposium at UC Davis on May 1, 2000.

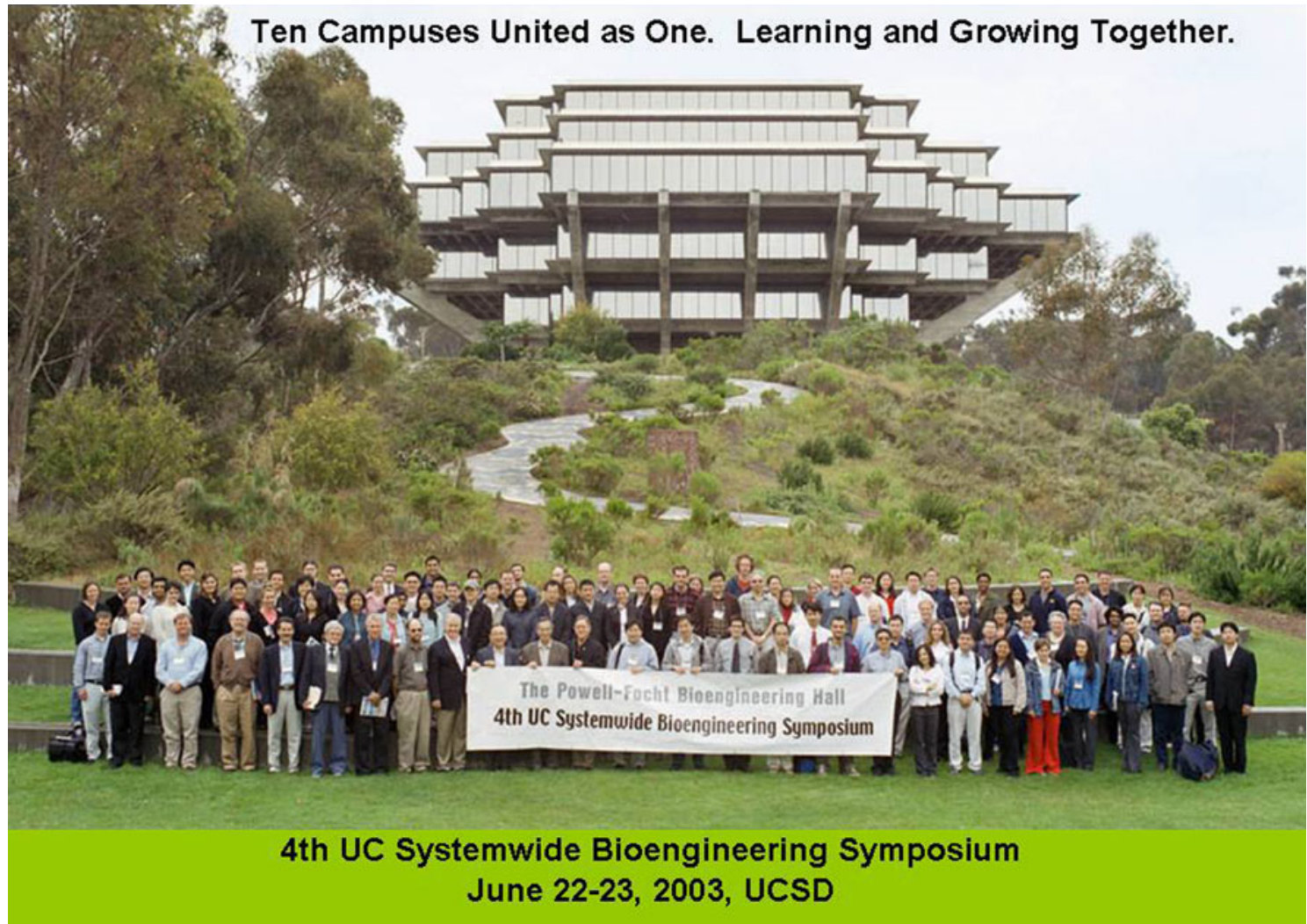

FIGURE 3. The Fourth UC System-wide Annual Bioengineering Symposium at UCSD on June 22, 2000.

enthusiastic participation by students and faculty. These 10 wonderful meetings brought together students, faculty, and research scientists from all 10 campuses and guest participants from industry, foundations, government, and other institutions to actively engage in interactions, collaborations, and innovations. 
TABLE 1. UC Bioengineering Departments/Programs.

\begin{tabular}{|c|c|c|c|}
\hline Campus & Name of Dept./Program & Chair/Director & Web Address \\
\hline UC Berkeley & Dept. Bioengineering & Matthew Tirrell & http://bioeng.berkeley.edu/ \\
\hline UC Davis & Dept. Biomed. Engineering & Kyriacos Athanasiou & http://www.bme.ucdavis.edu/ \\
\hline UC Irvine & Dept. Biomed. Engineering & Abraham Lee & http://www.eng.uci.edu/dept/bme/ \\
\hline UC Los Angeles & Dept. Bioengineering & Timothy Deming & http://www.bioeng.ucla.edu/ \\
\hline UC Merced & Bioengineering Majors & Aerial Escobar & https://eng.ucmerced.edu/soe/acad-prog/ \\
\hline UC Riverside & Dept. Biomed. Engineering & Jerome Schultz & http://www.bioeng.ucr.edu \\
\hline UC Santa Barbara & $\begin{array}{l}\text { Biomolecular Science } \\
\text { \& Engineering Program }\end{array}$ & Fyl Pincus & http://www.bmse.ucsb.edu/research/bioengineering \\
\hline UC Sata Cruz & Dept. Biomolecular Eng'g & Mark Akeson & http://biomedical.ucsc.edu/Bioengineering.html/ \\
\hline UC San Diego & Dept. Bioengineering & Shankar Subramaniam & http://www.be.ucsd.edu/o \\
\hline UC San Francisco & $\begin{array}{l}\text { Dept. Bioengineering } \\
\quad \& \text { Therapeutic Sciences }\end{array}$ & $\begin{array}{l}\text { Sarah Nelson } \\
\quad \& \text { Kathy Giacomini }\end{array}$ & http://bts.ucsf.edu/ \\
\hline
\end{tabular}

TABLE 2. UC System-wide Annual Bioengineering Symposia 2000-2011.

\begin{tabular}{llll}
\hline Year & UC Campus & \multicolumn{1}{c}{ Date } & \multicolumn{1}{c}{ Chair } \\
\hline 2000 & UC Davis & $4 / 30-5 / 01,2000$ & Maury Hull \\
2001 & UC Santa Barbara & $5 / 06-5 / 07,2001$ & Alison Butler \\
2002 & UC Berkeley & $5 / 05-5 / 06,2002$ & Thomas Budinger \\
2003 & UC San Diego & $6 / 21-6 / 22,2003$ & Shu Chien \\
2004 & UC Irvine & $6 / 26-6 / 28,2004$ & Steve George \\
2005 & UC Santa Cruz & $6 / 25-6 / 27,2005$ & Wentai Liu \\
2006 & UC Los Angeles & $6 / 24-6 / 26,2006$ & Benjamin Wu \\
2007 & UC San Francisco & $6 / 15-6 / 17,2007$ & Tejal Desai \\
2008 & UC Riverside & $6 / 20-6 / 22,2008$ & Victor Rodgers \\
2009 & UC Merced & $6 / 19-6 / 21,2009$ & Kara McCloskey \\
2010 & UC Davis & $6 / 17-6 / 19,2010$ & Angelique Louie \\
2011 & UC Santa Barbara & $6 / 13-6 / 15,2011$ & Frank Doyle \\
\hline
\end{tabular}

In June 2010, the System-wide Symposium began the second decade with a bang by returning to its birth site: UC Davis. The Symposium had the largest ever attendance (Fig. 5) and started the Grand Challenge for Entrepreneurism sponsored by TATRC. As we are planning for the 12th Annual System-wide Symposium in 2011, we look forward to our return to UC Santa Barbara for another great meeting. The tremendously successful and valuable Symposia rotating around all $10 \mathrm{UC}$ campuses for more than a decade are probably the only one of its kind anywhere, thanks to the great efforts of our colleagues at the 10 campuses and the support by everyone involved. These Symposia have played a major role in achieving the mission of the BIC to synergize the strengths of the UC campuses, in partnership with the National Laboratories, other universities, bioengineering-related industry, private foundations, and government agencies.

In this connection, I wish to express our most sincere thanks, on behalf of the BIC, to the generous support by the California Healthcare Institute, California Institute for Regenerative Medicine, Southern California Biomedical Council, TATRC, Whitaker Foundation, other universities such as Arizona State University, Georgia Institute of Technology, and University of Southern California, as well as many industrial firms. In the last 3 years, we received valuable support from the following industrial partners: Abbott Vascular, Agilent Technologies, Bio-Rad, Boston Scientific, Caliper Lifesciences, CRC Press, Genentech, Gilead, Instron, Penguin Computing, Penumbra, Philips, ResMed, SHRINK nanotechnologies, Springer, Technical Instruments, Third Rock Ventures, and Xradia Insight in 3D. We appreciate the support of the University of California (Office of the President, the 10 campuses, and UC Discovery) and national scientific organizations such as Biomedical Engineering Society (BMES), BMECareer Alliance, Institute of Physics, and Society of Photo-Optical Instrumentation Engineers (SPIE).

The strength of the BIC is based on those of the 10 campuses in the UC System and their synergism. Each campus has its unique areas of emphasis and expertise, as summarized in Table 3. The numbers of students (currently enrolled and most recently graduated) and faculty (both core and affiliated) are summarized in Table 4. The Bioengineering programs in the UC System have a total of nearly 3500 undergraduate student and almost 1000 graduate students (with over $800 \mathrm{PhD}$ students). During the past academic year, the 10 campuses graduated 561 B.S., 87 Masters, and 93 $\mathrm{PhD}$ students. Comparison of the graduated and enrolled student numbers indicates a continued expansion of the program pool. These well-trained students provide an important work force in areas related to biomedical engineering in California, our Nation, and beyond. The graduate and undergraduate students in each campus form professional organizations, including many active BMES Chapters, to enrich their learning experience and team activities, including interactions with industry. The Departments/Programs in the UC System have 176 core faculty and 277 affiliated faculty, as well as several hundred research 


\section{Bioengineering Institute of California (Ten Campuses United as One)}

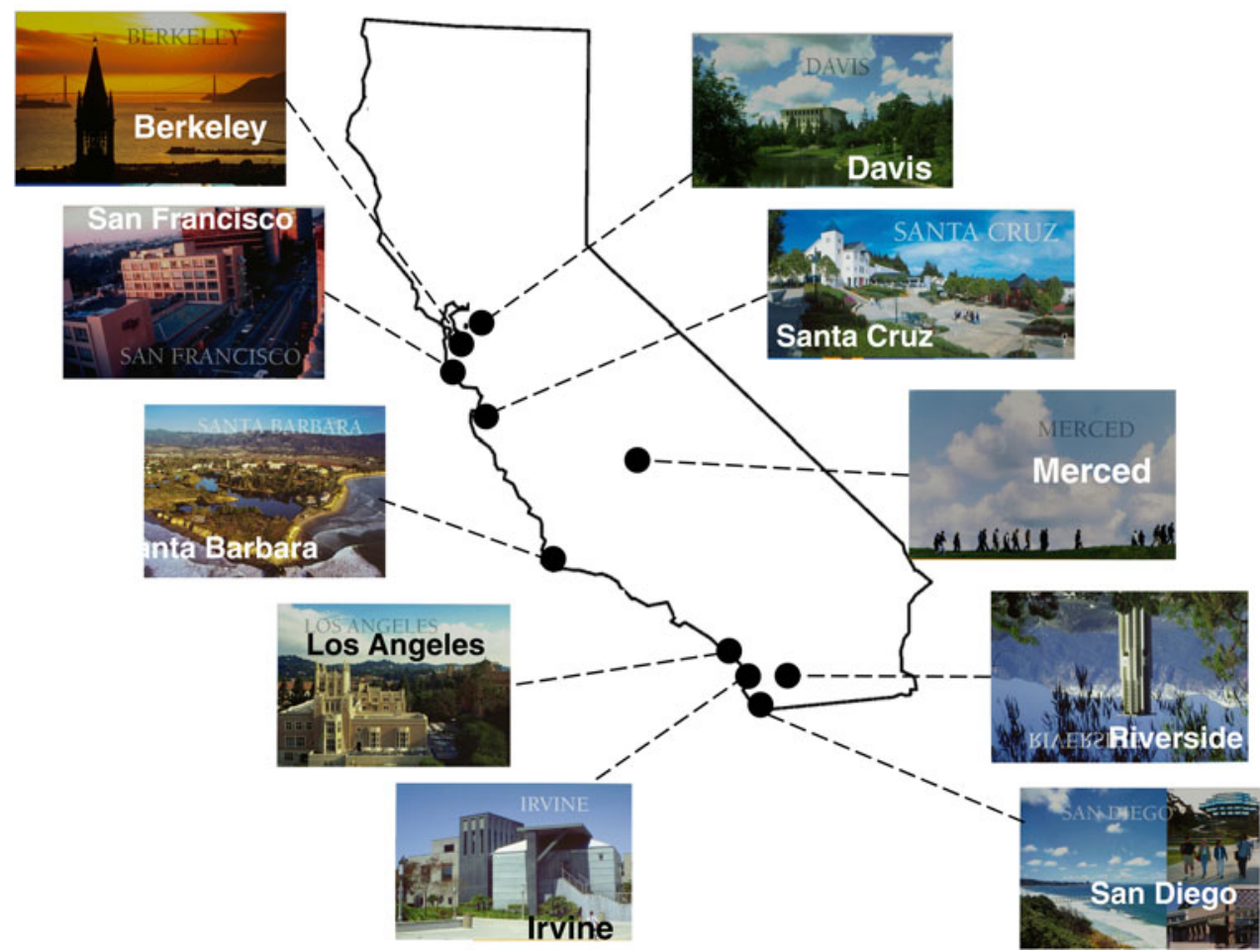

FIGURE 4. The 10 UC campuses in the Bioengineering Institute of California.

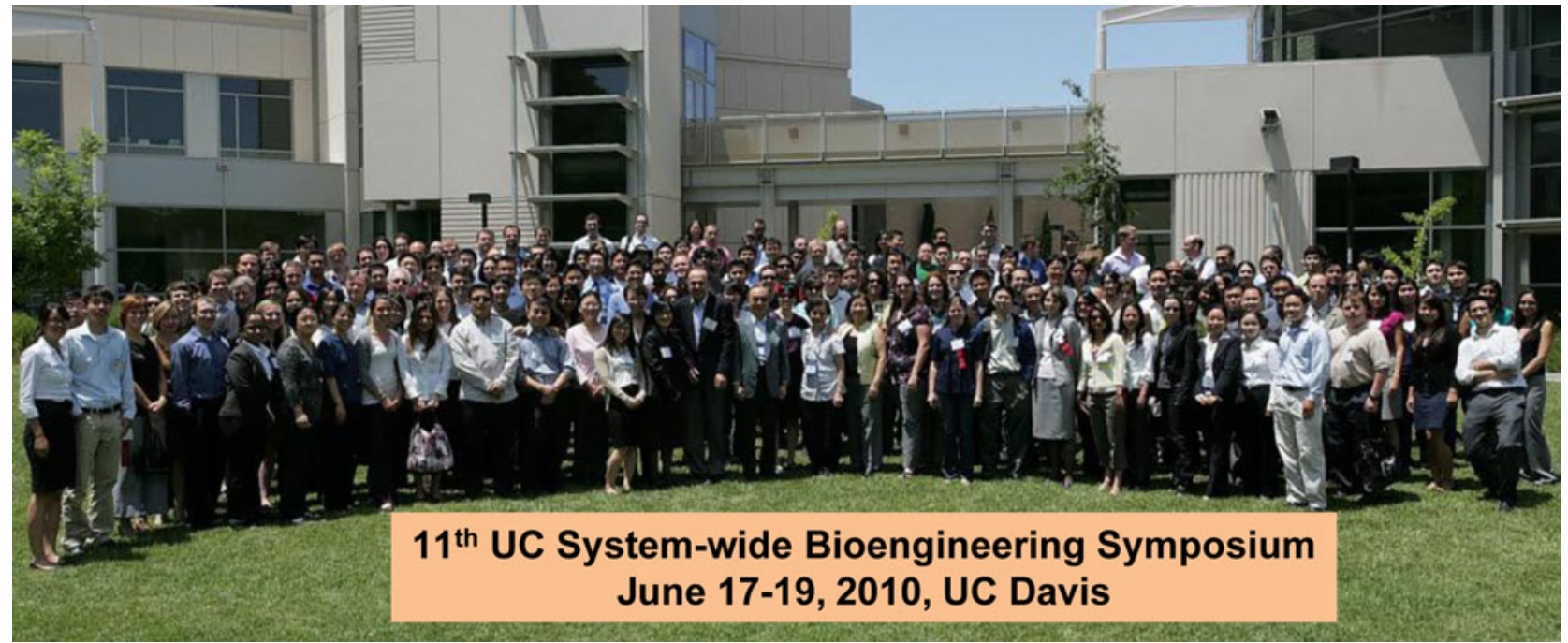

FIGURE 5. The 11th UC System-wide Annual Bioengineering Symposium at UC Davis on June 18, 2010.

scientists. They contribute importantly to the advancement of bioengineering research and education, and include recipients of many outstanding awards and recognitions. The data in Tables 3 and 4 provide a general overview of the expertise and summary information on research and education in the $10 \mathrm{UC}$ campuses. Collectively, they form a system that is almost unparalleled anywhere. These tables do not include the research and training activities in the National Laboratories (Lawrence Berkeley, Lawrence Livermore, and Los Alamos), 
TABLE 3. BE/BME Research Areas in the UC System.

\begin{tabular}{|c|c|c|c|c|c|c|c|c|c|c|}
\hline & UCB & UCSF & UCD & $\mathrm{UCl}$ & UCLA & UCR & UCM & UCSB & UCSC & UCSD \\
\hline Bioinfo. \& Comp. Biology & ++ & + & ++ & + & & & + & & ++ & + \\
\hline Biomaterials & & + & + & & ++ & ++ & ++ & ++ & & \\
\hline Biomechanics & ++ & + & ++ & & & + & & ++ & + & ++ \\
\hline Biomedical Imaging & & ++ & ++ & & ++ & ++ & & + & & + \\
\hline Biomedical optics & & + & + & ++ & & ++ & & & & \\
\hline Bio-MEMS \& Nanoscience & + & ++ & + & ++ & ++ & + & ++ & + & + & + \\
\hline Biomimetics & & & & & & & + & + & & \\
\hline Biomolecular Assembly & + & & & & + & & + & ++ & ++ & \\
\hline Biosensors & & & + & & & ++ & ++ & + & ++ & + \\
\hline Genomics, Proteomics & + & & & & & & & + & ++ & \\
\hline Molec. \& Cell. Engineering & & ++ & ++ & + & ++ & ++ & + & ++ & & ++ \\
\hline Molecular (Drug) Delivery & & + & & & + & + & & & & \\
\hline Neuroengineering & & ++ & & + & + & & & & & + \\
\hline Robotics & & & & + & & & & & + & \\
\hline Stem Cell Research & ++ & & + & ++ & + & + & ++ & & ++ & ++ \\
\hline Synthetic Biology & ++ & & & & & & & & & \\
\hline Systems Bioengineering & + & & & + & & & + & ++ & & ++ \\
\hline Tissue Engineering & + & ++ & ++ & ++ & ++ & + & ++ & & & ++ \\
\hline Wireless Health & & & & + & + & & & & & \\
\hline
\end{tabular}

+ indicates research areas being pursued.

++ indicates research areas with major emphasis.

Each campus entered a maximum of 5 " ++ " and 10 check marks overall. Therefore, there are other additional areas in some campuses that are not presented in this table.

TABLE 4. Current student enrollments, past-year graduates, and numbers of faculty in UC Bioengineering Programs.

\begin{tabular}{|c|c|c|c|c|c|c|c|c|}
\hline \multirow[b]{2}{*}{ Campus } & \multicolumn{3}{|c|}{ Current enrollment (2010) } & \multicolumn{3}{|c|}{ \# Graduated (2009-2010) } & \multicolumn{2}{|c|}{ Faculty number } \\
\hline & BS & MS & $\mathrm{PhD}$ & BS & MS & $\mathrm{PhD}$ & Core & Affiliated \\
\hline UC Berkeley ${ }^{a}$ & 427 & 16 & 164 & 120 & - & 26 & 30 & 4 \\
\hline UC Davis & 347 & 8 & 113 & 39 & 5 & 7 & 19 & 27 \\
\hline UC Irvine & 684 & 38 & 92 & 96 & 6 & 15 & 17 & 54 \\
\hline UC Los Angeles & 258 & 36 & 165 & 45 & 31 & 11 & 8 & 78 \\
\hline UC Merced & 105 & 5 & 13 & 18 & - & - & 3 & 20 \\
\hline UC Riverside & 342 & 11 & 31 & 22 & 2 & - & 9 & 40 \\
\hline UC Santa Barbara & 304 & 7 & 66 & 65 & 7 & 8 & 27 & 7 \\
\hline UC Santa Cruz ${ }^{\mathrm{b}}$ & 238 & 7 & 36 & 7 & 11 & 8 & 11 & 1 \\
\hline UC San Diego ${ }^{c}$ & 762 & 43 & 133 & 149 & 25 & 18 & 23 & 17 \\
\hline UC San Francisco ${ }^{a}$ & & (16) & $(164)$ & & & (26) & 29 & 29 \\
\hline Total & 3,467 & 181 & 813 & 561 & 87 & 93 & 176 & 277 \\
\hline
\end{tabular}

aUCB and UCSF have a joint Graduate Program. The graduate enrollment and graduates are listed for both, but counted only once in the Total.

'UCSC's figures represent the sum of Departments of Bioengineering and Biomolecular Engineering.

${ }^{\mathrm{C}}$ The figures for M.S. for UCSD include Master of Engineering students (10 enrolled and 9 graduated).

which are closely linked with the UC System. Furthermore, UC Campuses form Consortia with outstanding neighboring institutions. An example is the Sanford Consortium for Regenerative Medicine on the La Jolla Mesa, which is formed by the Salk Institute for Biological Studies, the Sanford-Burnham Medical Research Institute, the Scripps Research Institute, and UCSD to pursue collaborative, frontier stem cell research, including bioengineering.

In the UC system, there are also Organized Research Units (ORUs) that foster interdisciplinary research and training within each campus. Examples are the Institute of Engineering in Medicine in UCSD, Institute for Collaborative Biotechnologies at UCSB, Center for Bioengineering Research at UC Riverside, Center for Biomolecular Science and Engineering at UC Santa Cruz, etc. These ORUs provide interdisciplinary research and training related to bioengineering within each campus and contribute to the System-wide $\mathrm{BIC}$ as an MRU.

At the turn of the century, the State of California formed four California Institutes for Science and Inno- 
vation across UC Campuses. They are the California Institute for Quantitative Biosciences (QB3: UCSF, UCB and UCSC), California Institute for Telecommunications and Information Technology (CalIT2: UCSD and UCI), California Nanosystems Institute (CNSI: UCLA and UCSB), and Center for Information Technology Research in the Interest of Society (CITRIS: $\mathrm{UCB}, \mathrm{UCD}, \mathrm{UCM}$ and UCSC). All four California Institutes are based on two or more UC Campuses and have significant activities related to bioengineering.

The BIC MRU has established a modern information infrastructure for broadband inter-campus transmission, thus forming a network for research and teaching system-wide. This makes possible the sharing of database, broadcasting of teaching materials, teleoperation of specialized instruments, video conferencing, and telecommunication. Seminars have been broadcasted from one campus by videocast to other campuses. The BIC LearnBME website is a portal and teaching collaboratory for Bioengineering education that was initiated by a Special Opportunity Award from the Whitaker Foundation. This serves to synergize the collective strengths and expertise of the UC campuses in bioengineering education. The web address for BIC is http://www.bicmru.org/.

In summary, by fostering system-wide collaborations in research and education, the BIC has been able to synergize the expertise and activities of various campuses to advance biomedical engineering to a higher level than the sum of individual campuses.

The future goals of the BIC are to leverage on the accomplishments in the first decade to further enhance the System-wide Symposium, to initiate new research collaborations, to establish collective educational activities, and to collaborate with industry and government agencies, as well as other institutions. Together, we can achieve the common objectives of advancing the discipline of Bioengineering and benefiting the health and wellbeing of people.

\section{ACKNOWLEDGMENTS}

The author wishes to thank all the colleagues in the UC System for their marvelous collaborative efforts in making possible the functioning of the BIC, the successful holding of UC System-wide Symposia for over a decade, and the writing of this article. On behalf of the BIC, the author wishes to thank the University of California, its 10 campuses, the National Laboratories, other education and research institutions, industry, foundations, and government agencies (many of them are mentioned in this article) for their most valuable support and collaborations.

\section{OPEN ACCESS}

This article is distributed under the terms of the Creative Commons Attribution Noncommercial License which permits any noncommercial use, distribution, and reproduction in any medium, provided the original author(s) and source are credited. 